\title{
Postpartum Depression and the Social Construction of Motherhood: A Gendered Perspective
}

\author{
Samya Shinde \\ Assistant Professor, Department of Sociology, L.S. Raheja College of Arts and Commerce, Mumbai \\ Corresponding author: Ms. Samya Shinde \\ Email-samya.shinde@1sraheja.org
}

\begin{abstract}
Background: The objective of the paper is to explore the socio-cultural dimension that causes postpartum depression. Romanticized motherhood, family pressures and culture exert pressure on the new mothers who are expected to bask in the glory of being mothers negating their own motherhood experiences and challenges. Postpartum depression (PPD) is common form of depression for new mothers however the least recognized and often misunderstood as baby blues.

Methods: For the purpose of this research study personal face-to-face interviews were conducted with 30 new mothers being treated for postpartum depression.

Results: Respondents (21women) mentioned how the 40 days confinement period worsened their condition as they were engulfed with feelings of sadness and hopelessness since they were constrained to their homes. The 30 respondents were also given a list of statements to describe their feelings during the first month after their delivery.

Conclusion: Socio-culturally there is a propensity among women to subscribe to gender egalitarian attitudes and not engaging in gender consistent behaviour often affects them. Society has unrealistic expectations of how motherhood should be.
\end{abstract}

Keywords: Postpartum depression, Motherhood, Mental health, Social construction of reality.

(Paper received $-2^{\text {nd }}$ January 2018, Peer review completed $-13^{\text {th }}$ January 2018)

(Accepted $-16^{\text {th }}$ January 2018)

\section{INTRODUCTION}

"Mental illness is the most solitary of afflictions to the people who experience it; but it is the most social of maladies to those who observe its effects"- Michael MacDonald-eminent historian of psychiatry.

Gender is a critical determinant of health. Sociological interest in the area of mental health and illness emanates from the socio-cultural dimensions of mental health that differentiates between access to health on the basis of gender. What constitutes mental illness is gender biased. Symptom related to anxiety and depression is taken lightly in the case of women adding to their vulnerability. This also renders them illequipped to cope with the same. Women's physical and mental well-being is dependent on variety of factors that start from the immediate family in the formative years to the extended family in the later life after marriage. Women are at a greater risk during her life cycles due to reproductive cycles that play on the hormones as well as the social adjustments that a woman has to make throughout her life.

Women more often than men experience common mental disorders like depression, anxiety and panic attacks. WHO (2000) estimated that depression is more common and persistent in women than men. It estimates depression to be the $2^{\text {nd }}$ largest contributor of morbidity by 2020 with one in every 3 women worldwide to be affected by common mental disorder [1-2]. The NIMHANS survey on India's Mental 
Health (2015-2016) released its report in October 2016 reported that 1 in every 20 person suffers from depression and that the proportion of women suffering from depression is higher compared to men.

The risk factors and underlying causes affecting mental health of women is rooted in patriarchy affecting women at different stages. Right from childhood till reaching one's teenage years behaviour is defined and restricted by a certain set of norms and one has to adhere to certain set of social expectations failing which invites ridicule. During the adolescent years the demands of emotional availability of women start showing up which requires active family intervention. While on one hand family provides emotional care on the other hand there are clear restrictions of behaviour, certain expectations which are different for boys and girls. Adolescence is the period of bodily changes and most often the symptoms of depression and anxiety are viewed as part of what every girl goes through. Research has supported the fact that emotional labourwhere one expresses emotions as per others wishes-takes toll on women's mental health. The institution of marriage brings with it a plethora of expectations for women to conform to gender roles. Emotional abuse, domestic violence and sexual abuse within marriage is debilitating for women leading to severe mental health issues. Gender norms are reinforced socially, culturally and institutionally and the social roles that men and women occupy account for gender differences in rates of psychiatric disorder. Women very often hide their difficult feelings internalising it thus leading to depression. The social stress theory asserts that mental health problems are caused by exposure to social stress, vulnerability to social stress and the individual's limited ability to cope with stress due to low levels of social support and self-esteem [3].

The NIMHANS survey (2015-16) reveals that women are more prone to depression especially in the child rearing years. The survey estimates that about $15.3 \%$ to $23 \%$ women suffer from postpartum depression post-delivery and 1 in 6 new mothers suffer from symptoms of postpartum depression upto 6 months after delivery. The onset of postpartum depression starts a few weeks after childbirth. Often dismissed as baby blues it goes unrecognized. When baby blues continue even 2 weeks after delivery it requires medical intervention as these are signs of postpartum depression. The mother experiences severe mood swings, excessive crying, panic attacks, agitation, lack of sleep or oversleeping, worthlessness, hopelessness and feelings of harming either the baby or self [4].

\section{METHODOLOGY}

For the purpose of this research study personal face-to-face interviews were conducted with 30 new mothers being treated for postpartum depression. While the study is too small to make sweeping generalisations it is nevertheless significant to understand postpartum depression from a socio-cultural viewpoint and the social construction of motherhood.

Most of the mothers were first time mothers with only 1 mother having experienced childbirth earlier. The mean average of delivery is 28 years. The qualifications of the respondents range from graduates (17 women) to post graduate ( 8 women) and 5 women are undergraduates. 25 women are working professionals who on an average joined back 8 weeks post-delivery. Only 1 respondent had history of depression and was undergoing treatment when she delivered.

Though majority of the respondents (28 women) had family support the new mothers were never the focus and all attention shifted to the health of the new baby. Women were not allowed to have any moment of weakness or even of any doubt of weakness.

Respondents ( 21 women) mentioned how the 40 days confinement period worsened their condition as they were engulfed with feelings of sadness and hopelessness since they were constrained to their homes. While they agreed that this may be due to protect mother and child from infection this practice made them feel lonely. Having supportive husbands (6 women) made life post-delivery easier but many intrusive questions asked especially by the in-laws and elders in the family related to breastfeeding pressurised them especially when they were unable to breastfeed and made to feel guilty for not providing the baby with the best. While family supported taking care of the baby PPD was brushed aside and feelings of loneliness, mood swings and weeping was accepted as normal. Women were asked instead to concentrate on the new born and commented upon that since they have a wonderful baby; everything is fine how they can even think of being depressed. Unsupportive partners and in-laws (14 women) magnified the difficulties for working mothers making some lose opportunities for promotions (8 women). Lack of support from 
partners was viewed as a trigger of stress among women. This support was physical, emotional as well as not sharing the household responsibilities.

The 30 respondents were also given a list of statements to describe their feelings during the first month after their delivery. The analysis of post-delivery health status is as follows:

\begin{tabular}{|c|c|c|c|c|c|}
\hline Item & $\begin{array}{c}\text { Strongly } \\
\text { Disagree }\end{array}$ & Disagree & $\begin{array}{c}\text { Neither } \\
\text { Agree nor } \\
\text { disagree }\end{array}$ & $\begin{array}{c}\text { Agree } \\
\text { Strongly } \\
\text { agree }\end{array}$ \\
\hline $\begin{array}{c}\text { I had trouble sleeping even when baby } \\
\text { was asleep }\end{array}$ & 0 & 0 & 5 & 16 & 9 \\
\hline $\begin{array}{c}\text { I got anxious over small things } \\
\text { concerning my baby }\end{array}$ & 0 & 0 & 1 & 6 & 23 \\
\hline $\begin{array}{c}\text { I experienced mood swings } \\
\text { mind }\end{array}$ & 0 & 0 & 0 & 18 & 12 \\
\hline $\begin{array}{c}\text { I felt like I was losing control of my } \\
\text { I felt very lonely and alone }\end{array}$ & 0 & 0 & 1 & 17 & 12 \\
\hline $\begin{array}{c}\text { I wanted to hurt myself and felt death } \\
\text { was the only solution }\end{array}$ & 0 & 5 & 6 & 13 & 6 \\
\hline $\begin{array}{c}\text { I felt guilty that I did not feel as much } \\
\text { love for my baby as I should }\end{array}$ & 0 & 2 & 3 & 12 & 13 \\
\hline I felt I was a failed mother & 0 & 1 & 2 & 15 & 12 \\
\hline $\begin{array}{c}\text { I felt I had to hide what I was feeling or } \\
\text { thinking towards the baby }\end{array}$ & 0 & 3 & 2 & 14 & 11 \\
\hline I felt my baby was better off without me & 0 & 1 & 4 & 12 & 13 \\
\hline $\begin{array}{c}\text { I felt like I was not the mother I wanted } \\
\text { to be }\end{array}$ & 0 & 0 & 0 & 1 & 29 \\
\hline
\end{tabular}

In addition to the above questions related to their moods and feelings open ended questions were asked to express their feelings about the idea of being a mother and motherhood feelings post-delivery. The one to one discussion with them included questions on whether there were certain expectations of them from the family and whether these interfered with their act of motherhood as experienced by them. The excerpts of the few responses that have been recorded and presented in the paper:-

"My husband and I decided to have a baby and made all arrangements for the baby's arrival.....and then the baby arrived...The euphoria gave way to everything unexpected, I lost control and it was a nightmare the constant naggings from my mother-in-law and husband was terrible it was nothing I had imagined".

"I work and within 6 weeks of my delivery I had to report back... all hell broke loose... I was told to leave the job and concentrate on the baby...... I feel guilty and ask myself if I continue to work I will never forgive myself, but working is important or else I will go crazy".

"I tried to be a good mother and did everything that good mothers do- be attentive, constantly on my toes, always available; devoted to the baby's needs but I can't do it....I feel inadequate as a mother- the expectations are just too many."

"All through my life till I became a mother I was told motherhood is the most fulfilling experience. I waited for that moment .... my aches and pain are almost invisible to others...I think I gave it my best shot but I don't feel gratified by the tasks I am performing as a mother. I feel guilty I don't know what to do" "I find it difficult to accept that I am unable to be the kind of mother I always imagined and dreamed of being as was projected to me by my mother and matrimonial family... I am not able to be a mother."

"I was unable to lactate properly. Bottle feeding even after pumping milk was a strict no...no... I was so worried and intimidated feeling like a fool because I was even afraid to ask anything. I lost control and this pressure caught onto me and I started neglecting myself and also the baby".

"Expectations around parenting caught onto me; constantly nagged on when to sleep...what to do oh my god. Constantly.... I am not the baby lay off judging me for heaven's sake." 
"I was made to think that my weeping, mood swings post-delivery was normal....but I knew something was just not right....I didn't feel myself and broke down at the slightest prick from anyone questioning me about the care I took of my new-born. I felt totally disconnected with the little one and felt miserable."

"I was always carefree and looked forward to motherhood. But post motherhood I saw myself transformed from a carefree young lady to an agitated, irritable mother within a few months of delivery. I was freaking out."

"My family members said that since I wanted to have a baby and now that I have one who is fit and fine then how can I say I am depressed. All is fine with you. This discouraged me to talk about what I was feeling. I felt very guilty because my feelings towards the baby were not very positive".

"I would be just lost glaring into empty spaces wondering what is I doing. I would look down the balcony wanting to jump..."

"I underwent the traditional 40 days confinement and felt suicidal since I felt I was not able to give the baby the care he needed."

Through these experiences of women we can deepen our understanding about the relation between gender, motherhood and mental health. Family pressures take a toll on the new mothers who anyways are experiencing hormonal changes as well as the aches and pains associated with delivery.

\section{DISCUSSION}

The discourse on motherhood often mystifies the role of a mother at the cost of the individual women placing unreasonable demands on her largely shaped by culture. The interviews revolved around the experiences of women as mothers and the pressures of motherhood in order to draw a co-relation between onset of PPD and the following of the ideals of motherhood.

Feminist sociologist and psychoanalyst Nancy Chowdorow argues that women's mothering role is taken for granted and rarely acknowledged though it is of profound importance for the family structure. She argues that being a mother is a task not an instinct. She argues that "contemporary reproduction of motherhood occurs through social structurally induced psychological processes."[5]. Adrienne Rich, a feminist writer in her book 'Of Women Born: Motherhood as experience and institution' conveys the complexity of maternal experience [6]. She argues that society places unreasonable demands on mother romanticising their role as provider of perfect and constant love. Motherhood is fraught by many contradictions and hardships. Eulogising motherhood and criticising infertile women; considered akin to devils; have shaped the discourse on motherhood-much more defined by men. Motherhood narratives emphasise the positive qualities of this condition every woman should experience namely feeling blissful, being tender, content, divine, positive etc. Motherhood narratives revolve around myths where motherhood is perceived as a blissful and magical experience rendering the woman incomplete without it. The pressure society puts on women to be perfect triggers the stress in women who are expected to reproduce and when they do it would be one of the happiest and blissful moments of their life. What is often missing in our motherhood narratives is that childbirth has a psychological and physical impact on the woman but soon after childbirth the focus shifts away completely from the new mother to child rearing and her various pains and aches along with hormonal imbalances are not dealt with.

However, one needs to learn from women's experiences to understand what motherhood means. Motherhood is fraught with contradictions where the woman ceases to be an individual herself but instead viewed as someone who is expected to change her mind set redirecting previous mental organisations, previous set of values and needs and cope with the duties and responsibilities of motherhood. Psychologist David Stern in his book 'The Motherhood Constellation' and 'The Birth of a Mother' explains how becoming mother is an identity shift for a woman who experiences physical and psychological changes [7]. However medical community has unexplored the process of becoming a mother and has largely focussed on the baby. Maternal mind-set in its quest to strike a balance between motherhood and work often places unnecessary stress on the woman making it complicated to reconcile the two interconnected yet different worlds. The feelings of guilt, inadequacy and loneliness take a toll on the woman adding to her already fragile state of mind due to interplay of hormones thus putting a new mother at a risk of PPD. 
Motherhood is not innate but acquired through time. The naturalness of motherhood has been criticised as motherhood is also a socio-cultural construct. Motherhood from social constructionist perspective rejects the assumption of motherhood traits and practices as being natural, essential and inevitable; rather it is a result of processes of social construction. Althusser's Ideological State Apparatus helps understand motherhood as an acquired state of mind. We are born in an ideology reinforced by certain institutions and we internalise these ideologies in a way without us challenging them [8]. Thus, the notion of ideal motherhood has to do with the social construction of motherhood- the perception that behaviour is determined by expectations that society assigns to the position rather than individual characteristics and experiences with society prescribing formula for motherhood. Gramsci's concept of hegemony- where one viewpoint overpowers all others also plays an important role in the social construction of motherhood [9]. The patriarchal notion aims to suppress woman and restrict her to the domestic sphere of life thus curbing her individuality.

Gender theorist and psychoanalyst Judith Butler in her book Gender Trouble shows how gender and sex are socially constructed. Gender, according to Butler, "is performatively constituted by the very 'expressions' that are said to be its results" [10]. Gendered traits and dispositions are performances influenced by culture and not a voluntary choice. She argues that maternity also is a social construct thus defying the idea of motherhood being natural. Mothers engaging in mothering feel guilty when they leave their child in the hands of the caretaker or sometimes alone and their choices of working outside are undermined by invoking morality of their choices and whether they are adequately performing their role as mothers. Motherhood narratives have viewed mothers as self-sacrificing mortals to uphold the morality of being mothers. The superwoman-supermom syndrome that woman get caught in make them experience defeat and disappointment not following the codes of being 'good mothers'. Post-modernist feminist analysts argue with regard to intensive mothering that mothers should be respected for their legitimate aspirations and desires. Ruddick argued that one needs to demystify and de-gender mothering ideology and specific acts associated with mothering needs to be shared by men. She refused to define mothering as a specifically female activity [11]. It was defined as a sex neutral activity.

Carrie Wendell-Hummel, University of Kansas, study of women suffering from symptoms of perinatal mental health disorders found that pressure to breast feed, sleep deprivation and unhelpful partner's exacerbated postpartum depression. She describes "Motherhood is thought to bring total self-fulfilment and happiness, and mothers are expected to perform their duties perfectly with little assistance from others". Her research also highlights how new moms struggling with breast feeding are made to feel guilty for not breastfeeding children triggering postpartum depression [12].

\section{CONCLUSION}

Issues of women's health often get limited to the sexual and reproductive health and rarely touch upon mental health. Socio-culturally there is a propensity among women to subscribe to gender egalitarian attitudes and not engaging in gender consistent behaviour often affects them. Society has unrealistic expectations of how motherhood should be. What restrain new mothers from seeking help are embarrassment, guilt and shame they feel about not being perfect mothers. While there is no denying the fact that women experience hormonal changes after birth the child care stress as well as lack of support makes women more susceptible to postpartum depression. Awareness about postpartum depression is necessary and not something to be ashamed of because it is a medical condition and the help of family, friends and society at large can go a long way in mitigating the problem.

Sociologists have for too long concentrated only on causes of mental health issues and risk factors leading to mental health. There is an urgent need to engage with women's bodies in a healthy manner. What is actually required is an understanding of real human beings who are trying to make sense of their lives living with postpartum depression. Narratives around motherhood need to be demystified and the experiences of women suffering from depression need to be shared and understood. Sensitizing family members, doctors, and health care providers to identify signs of depression can be a viable option to remedy the situation. 


\title{
REFERENCES
}

1. Basu S. Mental health concerns for Indian women. Indian J Gender Stud 2012;19(1):127-36.

2. Srivastava K. Women and mental health: Psychosocial perspective. Industr Psychiatry J 2012;21(1):1-3.

3. Stern G, Kruckman L. Multi-disciplinary perspectives on post-partum depression: an anthropological critique. Soc Sci Med 1983;17(15):1027-41.

4. Beck CT. Predictors of postpartum depression: an update. Nurs Res 2001;50(5):275-85.

5. Chodorow NJ. The reproduction of mothering: Psychoanalysis and the sociology of gender. Univ of California Press; 1999.

6. Rich A. Of woman born: Motherhood as experience and institution. WW Norton \& Company; 1995.

7. Stern DN, Bruschweiler-Stern N. The birth of a mother: How the motherhood experience changes you forever. Basic Books; 1998.

8. Althusser L. Ideology and Ideological State Apparatuses' in Lenin and Philosophy and other Essays. London: New Left Books ; 1971.

9. Hoare Q, Nowell-Smith G. Selections from prison notebooks. Lawrence \& Wishart; 2005.

10. Butler J. Gender trouble: Feminism and the subversion of identity. Routledge; 2011.

11. Ruddick S. Maternal thinking: Toward a politics of peace. Beacon Press; 1995.

12. Crossley ML. Breastfeeding as a moral imperative: An autoethnographic study. Feminism Psychol 2009;19(1):71-87.

\author{
$* * * * * * * * * * * * * * * * * * * * *$ \\ Acknowledgements - Nil \\ Conflict of Interest - Nil \\ Funding - Nil
}

